form; following, except last, moniliform, enlarging and becoming quadrate. Posterior ocelli as far from one another as from the eye-margin, each connected to the eye-margin by a raised line. Pronotum with a series of large punctures along its posterior edge. Mesonotum shining, almost impunctate; parapsidal furrows complete, converging behind, of equal width throughout; lateral lobes of mesonotum scarcely depressed; a deep foveate impression in front of the tegula. Scutellum with two large hoof-shaped foveæ at base, at apex with two small circular ones. Metathorax with a carina in the shape of an inverted V. Petiole twice as long as broad, with three strong longitudinal carinæ above,and a weaker lateral one, marking off four shallow grooves; second segment with the base raised and medially notched from behind; its median furrow extending nearly to the middle. Pro- and mesopleuræ smooth and shining, each margined by a raised line; metapleura pubescent, coarsely reticulate. Legs stout. Wings strongly pubescent, except at extreme base.

One female from Independencia, Parahyba, Brazil, Mann and Heath.

This species resembles G. sulcaticeps Kieffer, differing by its larger size, longer petiole, shorter first and second flagellar joints and longer scape. In certain lights the front shows a trace of the median lanceolate area present in sulcaticeps.

\title{
NOTE ON THE MOUTHPARTS OF ORTHOPTERA.
}

\author{
By H. H. Nininger, \\ Palmera College, Lordsburg, California.
}

This paper is presented for the purpose of calling attention to an error which appears in some of our most widely used textbooks on general zoölogy and entomology, as well as in other works which deal with the anatomy of Orthoptera.

For several years I have noticed the error, and always find it necessary to warn students against the tendency to see and draw the mouthparts of the "grasshopper" as they appear in the textbook instead of drawing them correctly from the specimen. For the drawings commonly used in text-books are not only anatomically incorrect, but are also unreasonable. For example, if one refers to Lang's Comparative Anatomy, Part 1, p. 446; or to Parker and Haswell, Vol. 1., p. 621, one finds the mandibles of the Blattidæ represented as two organs identical in form; each bearing three sharp-pointed teeth, which are arranged in exactly corres- 
ponding positions. The cutting edges of both mandibles are beveled in exactly the same manner, on the same side, so that were the cutting edges brought together, the point of each tooth on one mandible would come into direct contact with the corresponding tooth on the opposite mandible. Upon a moment's reflection it is clear that such an arrangement would be utterly useless as an organ of mastication. By the use of an ordinary lens one can easily see that such is not the structure, but that the mandibles of the cockroach have their cutting edges quite different the one from the other. Both have toothed edges; but the corresponding teeth on the different mandibles are not exactly alike and never borne in the same position; and are so arranged that those of the left mandible overlap those of the right mandible. This is accomplished by both cutting edges being beveled, the one in the opposite manner from the other so that in coming together they form a crushing apparatus. This structure I have taken pains to show in the accompanying drawing (fig. 1), made from a specimen.

Insects more commonly used to illustrate the mouthparts of the class are the locusts. The mandibles of Melanoplus femurrubrum as represented in Linville \& Kelly's General Zoölogy, or Comstock's Manual of the Study of Insects; and those of Schistocerca americana represented in Sanderson's Insect Pests of the Farm, Garden and Orchard, all present the same kind of error as that pointed out in the preceding paragraph. All show the two mandibles exactly, or very nearly alike. Unfortunately this error is of such a nature as to obscure the highly specialized structure of these organs for their function of mastication, for the drawings referred to above more nearly represent the true nature of the mandibles of carnivorous insects than those of the vegetableeating locusts. I have examined many specimens upon this point, representing no less than forty different species and I herewith present several drawings which I have made from specimens selected from various species to show the variations which occur in the mandibles of the locusts. The drawings are made from mandibles mounted in the same position as when closed in the living specimen; but separated enough to show the grinding surface of the right mandible. 


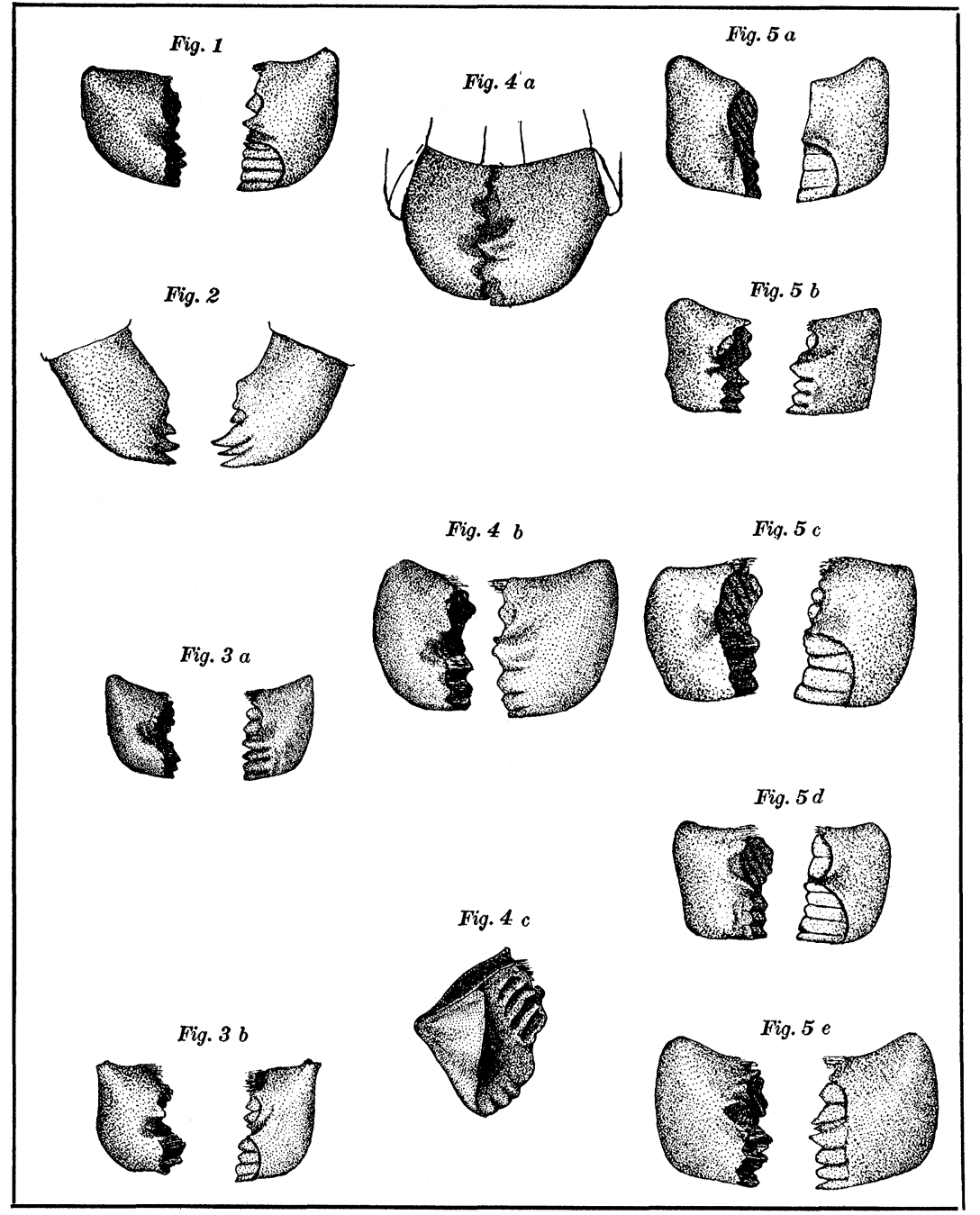

Mandibles of Various Locusts.

Fig. 1, Hippiscus tuberculatus; fig. 2, Cockroach; fig. 3a, Melanoplus femurrubrum; fig. 3b, Schistocerca alutacea; fig. 4a, Schistocerca americana, mandibles closed; fig. 4b, same, mandibles separated; fig. 4c, same, left mandible turned over to show grinding surface; fig. 5a, Syrbula sp.; fig. 5b, Melanoplus differentialis; fig. 5c, Disesteira carolina; fig. 5d, Encoptolophus sordidus; fig. 5e, Melanoplus differentialis 

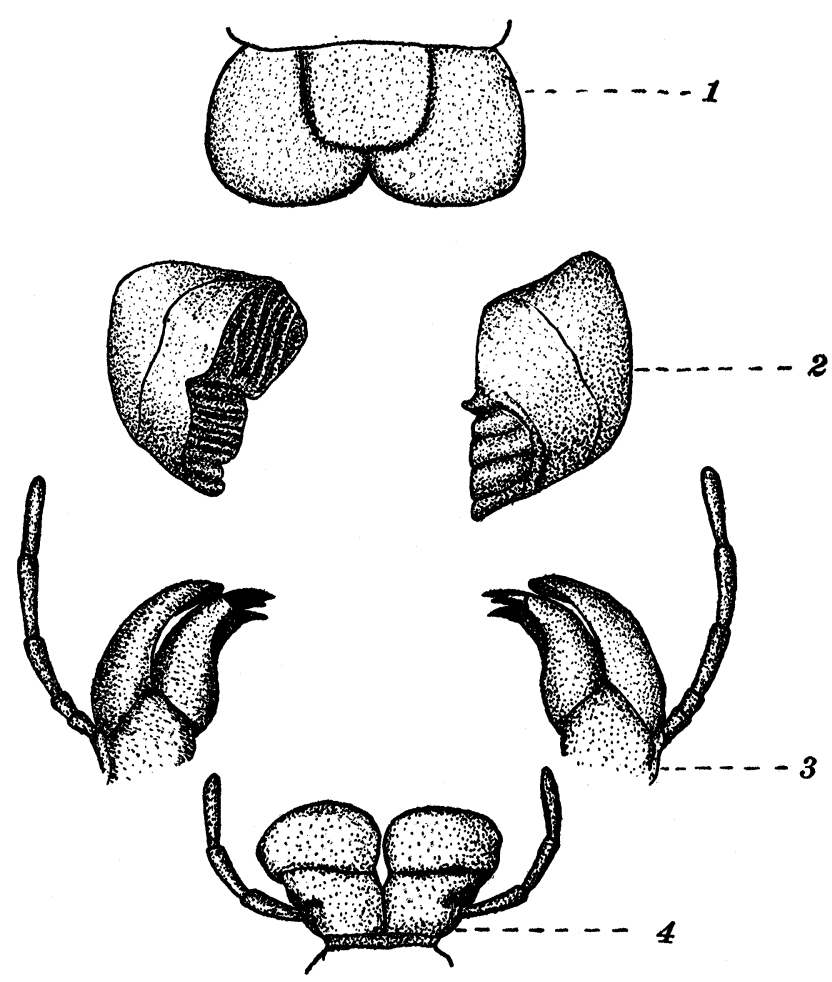

Fig. 1. Mouthparts of Locust, Genus Hippiscus. (Hypopharynx omitted.) 1, labrum; 2. mandibles; 3 , maxillæ; 4, labium.

Some of the constant characteristics of the mandible of locusts may be stated as follows:

1. The left mandible is generally slightly, and sometimes considerably larger than the right one; and projects beyond it ventrally . when closed.

2. The distal ends of the two mandibles are always beveled, the one in the opposite manner from the other so that when the mandibles are closed these beveled surfaces are contiguous throughout.

3 . When the mandibles are closed the anterior aspect presents the cutting edges meeting, not on the median line, but always to the right of it. (Plate 1, fig. 4a). 
4. The posterior part of the contact surface of each mandible is fitted for cutting, while the anterior part is fitted for grinding or crushing. (Plate 1, fig. 4c).

McPherson, Kansas.

January 15, 1914.

Now Lordsburg, Calif.

\section{NOTE ON THE HARRIS COLLECTION OF HETEROPTERA.}

\section{By J. R. de la Torre Bueno.}

During a recent visit to Boston, through the courtesy of Prof. C. W. Johnson I had the good fortune to examine the Harris collection of Hemiptera. Many of the insects, as is well known, passed through the hands of Thomas Say and were named by him and in the absence of types of his species they may be so regarded. The late Prof. P. R. Uhler also examined these insects at leisure and based on his study his authoritative paper "Notices of the Hemiptera Heteroptera in the Collection of the late T. W. Harris, M.D." 1

The custodian of the Boston Society of Natural History is to be congratulated on the excellent condition of these precious relics. Some one or two have suffered from Anthreni, but considering the great age of the collection, the bulk of the specimens are in a marvellous state of preservation. I shall not extend myself to repeat all the details given in the paper by Uhler cited, but certain notations on a few of the species will serve to clear up one or two obscure points.

Lygoeus turcicus Fabr., No. 54. The specimens from Michigan under this label are the only ones correctly named. The others are Lygous kalmii Stal, which is not mentioned by Uhler.

Gonianotus marginepunctatus Wolff, No. 65. The specimen under this label and number is the common Eastern Emblethis vicarius Horv.

Naucoris poeyi No. 148, "Florida, Doubleday" is Pelocoris carolinensis Bueno, characteristic.

Ranatra fusca P. B. No. 151, Harris No. 65, determined by Say according to Dr. Harris' manuscript catalogue, is undoubtedly R. protensa Mont. It is certainly not nigra H. S., as a careful

1 Proc. Bost. Soc. N. H., XIX, 365-446, 1878. 

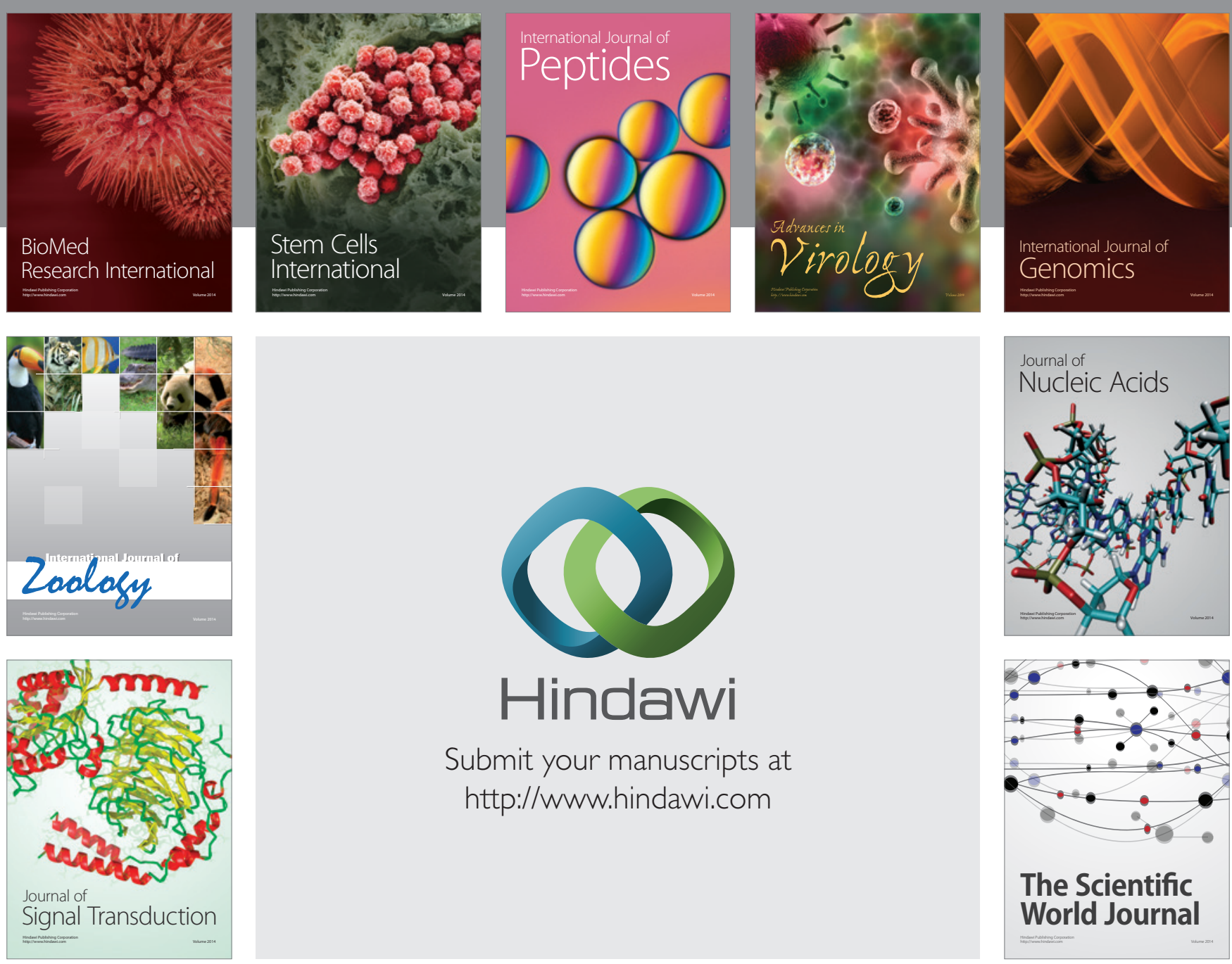

Submit your manuscripts at

http://www.hindawi.com
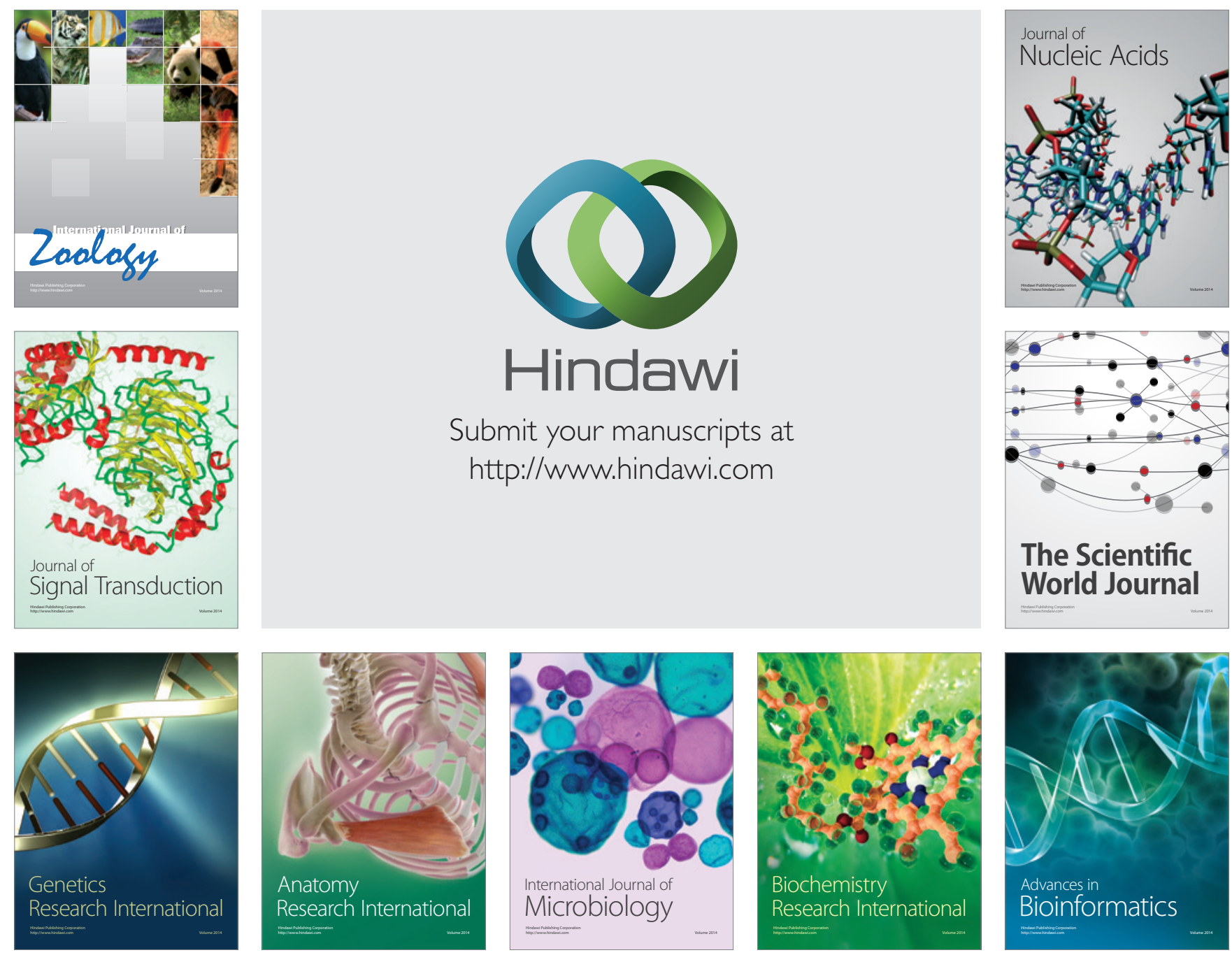

The Scientific World Journal
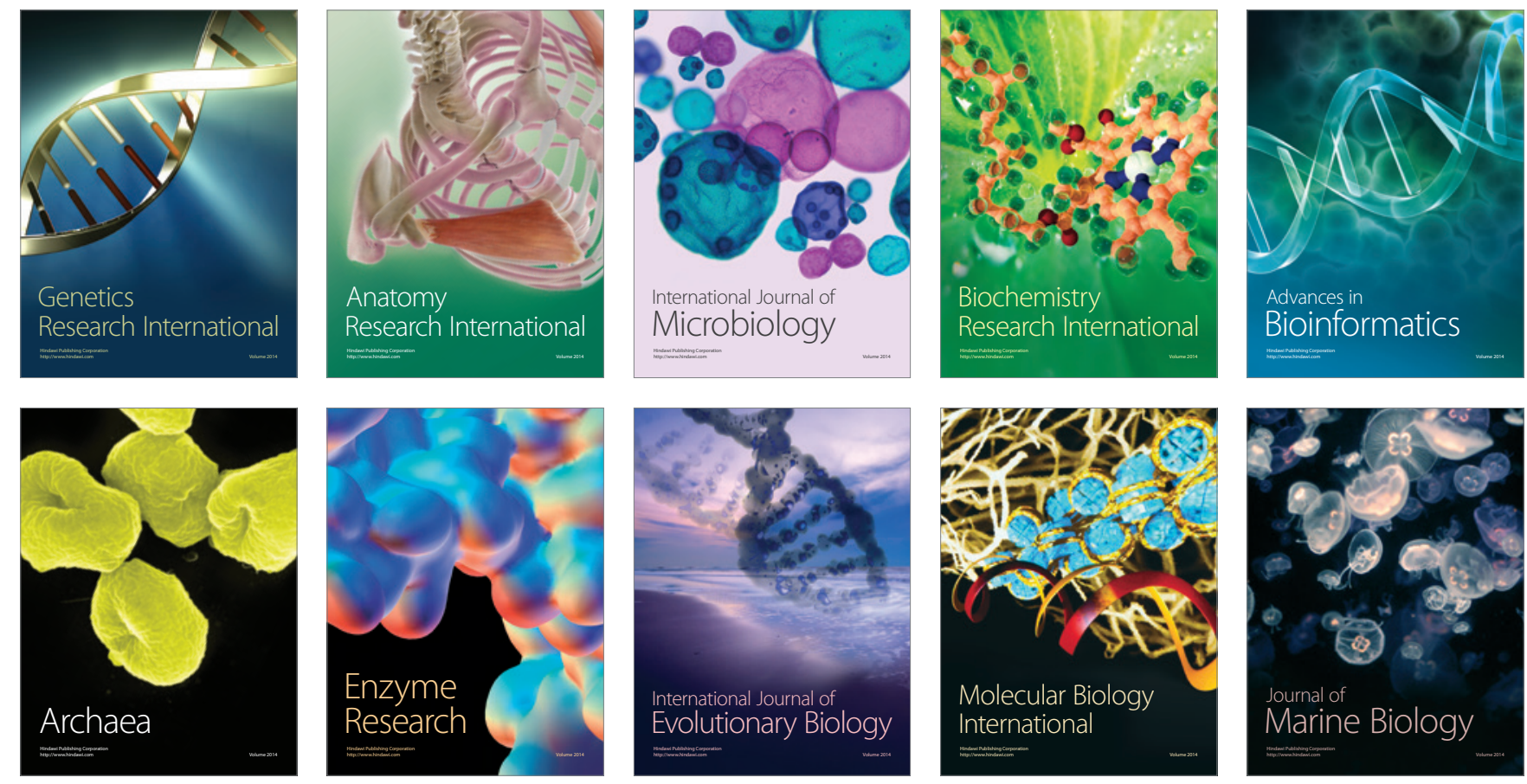